\title{
Electromagnetic Compatibility Problems in LTE Mobile Networks 800 MHz Frequency Band
}

\author{
Evaldas Stankevicius ${ }^{1}$, Arturas Medeisis ${ }^{1}$, Sarunas Paulikas ${ }^{1}$, Aurimas Anskaitis ${ }^{1}$ \\ ${ }^{I}$ Department of Telecommunications Engineering, Vilnius Gediminas Technical University, \\ Naugarduko St. 41-211, LT-03227 Vilnius, Lithuania \\ evaldas.stankevicius@rrt.lt
}

\begin{abstract}
This paper examines the LTE UE (Long-Term Evolution User Equipment) in $800 \mathrm{MHz}$ frequency band (the so-called digital dividend) interference to Short Range Devices (SRD) in the band of $863 \mathrm{MHz}-870 \mathrm{MHz}$. The fundamental objective of this research is to evaluate the probability of interference and influence of LTE UE emission mask in this regards. The study was performed in two methods: theoretical - simulations with SEAMCAT software and practical measurements to verify gathered results in simulations. The results of this paper characterize the required technical conditions for LTE mobile networks deployment in $800 \mathrm{MHz}$ band.
\end{abstract}

Index Terms-Electromagnetic compatibility, Interchannel interference, 4G mobile communication, UHF communication.

\section{INTRODUCTION}

The World Radiocommunications Conference in 2007 designated on an essential base the so-called digital dividend frequency band $(790 \mathrm{MHz}-862 \mathrm{MHz})$ to land mobile networks in Region 1 countries from 2015. The administrations from Region 1 could exploit this frequency band for land mobile networks before 2015, but only with the appliance to the Radio Regulations provisions [1].

Region 1 countries in 2009 decided to establish a decision which would guide the involved countries on technical and regulatory framework in the band $790 \mathrm{MHz}-862 \mathrm{MHz}$ in order to meet the growing shortage of radio frequency in mobile networks field [1], [2].

Mobile operators have the resources to expand their networks, but it becomes increasingly difficult to avoid interference between adjacent radio stations due to ever growing density of wireless apparatus [3], [4].

This study was conducted to help clarify the situation in the newly forming LTE cellular network called as digital dividend. The LTE frequency band $(790 \mathrm{MHz}-862 \mathrm{MHz})$ is quite close to the Short Range Devices band $(863 \mathrm{MHz}-$ $870 \mathrm{MHz}$ ) [5]. SRD can be called such facilities as: cordless headphone, intruder alarm, radio microphone, smart meter, telemetry, medical device, RFID (Radio-Frequency Identification) and etc. This paper investigates a possible situation in which LTE device is in the same room with the SRD unit. So the distance between LTE and SRD could be some meters.

Without this type of analysis LTE mobile networks could not be properly implement in the $800 \mathrm{MHz}$ band. LTE system in this frequency band has not to increase harmful interference level between neighbouring frequency ranges, e.g., DVB-T (Digital Video Broadcasting-Terrestrial) and SRD. The mentioned task had been raised by European Commission EC [6]. All administrations and industries from Europe had a possibility to contribute to this issue. The results of this analysis clarify the co-existence conditions between LTE and SRD.

First of all studies were carried out using SEAMCAT software [7]. SEAMCAT enables statistical simulation of different radio network scenarios in order to perform adjacent or co-channel electromagnetic compatibility cases. Then all simulations repeated practically using LTE signal generator and real SRD devices.

\section{LTE $800 \mathrm{MHZ}$ BAND SPECIFICATION}

The official CEPT document - Report 31 terminates that the prefigured frequency plan for the frequency band $790 \mathrm{MHz}-862 \mathrm{MHz}$ should be applied on the FDD (Frequency Division Duplex) mode. The frequency arrangement is stated in [8]: $791 \mathrm{MHz}-821 \mathrm{MHz}$ band as downlink, $832 \mathrm{MHz}-862 \mathrm{MHz}$ band as uplink, $821 \mathrm{MHz}-$ $832 \mathrm{MHz}$ band as duplex gap and $790 \mathrm{MHz}-791 \mathrm{MHz}$ band as guard band from DVB-T.

The LTE mobile networks in $800 \mathrm{MHz}$ frequency band can have influence to DVB-T services in the lower block of the LTE frequency band and with SRD in the upper side of the LTE frequency band. The frequency separation is relatively short, so there is possibility to identify electromagnetic compatibility problems.

TABLE I. 3GPP TS 36.101 LTE UE SPECTRAL EMISSION MASK [9].

\begin{tabular}{|c|c|c|c|c|}
\hline \multicolumn{5}{|c|}{ Spectral emission mask according to 3GPP recommendation } \\
\hline $\begin{array}{c}\text { fOOB } \\
{[\mathbf{M H z}]}\end{array}$ & $\begin{array}{c}\mathbf{5} \\
{[\mathbf{M H z}]}\end{array}$ & $\begin{array}{c}\mathbf{1 0} \\
{[\mathbf{M H z}]}\end{array}$ & $\begin{array}{c}\mathbf{1 5} \\
{[\mathbf{M H z}]}\end{array}$ & $\begin{array}{c}\text { Measurement } \\
\text { bandwidth }\end{array}$ \\
\hline $\pm 0-1$ & -15 & -18 & -20 & $30 \mathrm{kHz}$ \\
\hline $\pm 1-2.5$ & -10 & -10 & -10 & $1 \mathrm{MHz}$ \\
\hline $\pm 2.5-2.8$ & -10 & -10 & -10 & $1 \mathrm{MHz}$ \\
\hline $\pm 2.8-5$ & -10 & -10 & -10 & $1 \mathrm{MHz}$ \\
\hline $\pm 5-6$ & -13 & -13 & -13 & $1 \mathrm{MHz}$ \\
\hline $\pm 6-10$ & -25 & -13 & -13 & $1 \mathrm{MHz}$ \\
\hline $\pm 10-15$ & & -25 & -13 & $1 \mathrm{MHz}$ \\
\hline $\pm 15-20$ & & & -25 & $1 \mathrm{MHz}$ \\
\hline
\end{tabular}

This study assumes that LTE User Equipment uses 10 
MHz channel (852 MHz-862 MHz - most upper channel), the maximum available resource blocks (leads to maximum emission power) -50 , bitrate $-20 \mathrm{Mbit} / \mathrm{s}$. Table I shows the OOB (Out-of-Band) requirements in unwanted domain corresponding to 3GPP TS 36.101 recommendation (ETSI reference number TS 136 101) [9].

It would need to follow the principle that the resolution bandwidth (RBW) of the measuring device should be similar to the measurement bandwidth (MBW). In order maintain an acceptable level of measurement sensitivity and efficiency, the RBW should be narrower than the MBW.

\section{SRD MAIN INFORMATION}

The $863 \mathrm{MHz}-870 \mathrm{MHz}$ frequency band are available for SRD applications within sub-bands as already introduced in ERC Recommendation 70-03 [5]. The Short Range Devices technical parameters are described in the list below according to Annexes of ERC Rec. 70-03:

- Annex 1: Non-specific Short Range Devices;

- Annex 7: Alarms;

- Annex 10: Wireless microphones;

- Annex 13: Wireless Audio Applications.

The following Table II shows the parameters which were used in the SEAMCAT simulations. SRD were considered as a victims receivers.

TABLE II. PARAMETERS OF SHORT RANGE DEVICES [5], [10]-[12].

\begin{tabular}{|c|c|c|c|c|}
\hline Rec. 70-03 & Annex 1 & Annex 7 & Annex 10 & Annex 13 \\
\hline $\begin{array}{c}\text { Bandwidth } \\
\text { [kHz] }\end{array}$ & 100 & 25 & 200 & 50 \\
\hline $\begin{array}{c}\text { Sensitivity } \\
\text { [dBm] }\end{array}$ & -101 & -107 & -90 & -104 \\
\hline $\begin{array}{c}\text { C/(I+N) } \\
\text { [dB] }\end{array}$ & 8 & 8 & 17 & 8 \\
\hline Selectivity & EN 300 220 & EN 300 220 & EN 301 357 & EN 300 220 \\
\hline $\begin{array}{c}\text { EIRP } \\
\text { [dBm] }\end{array}$ & 14 & 14 & 14 & 10 \\
\hline $\begin{array}{c}\text { Operation } \\
\text { range [m] }\end{array}$ & 30 & 30 & 30 & 30 \\
\hline Antenna & \multicolumn{4}{|c|}{ Omni directional 0 dBi gain } \\
\hline $\begin{array}{c}\text { Frequency } \\
\text { [MHz] }\end{array}$ & 868.1 & 869.65 & 864.25 & 864.975 \\
\hline
\end{tabular}

In measurements only Non-specific SRD were used to verify results obtained in SEAMCAT simulations.

\section{INTERFERENCE SCENARIO USING SEAMCAT}

\section{A. Interference Scenario I}

The following Fig. 1 shows the test plan used for simulations with SEAMCAT.

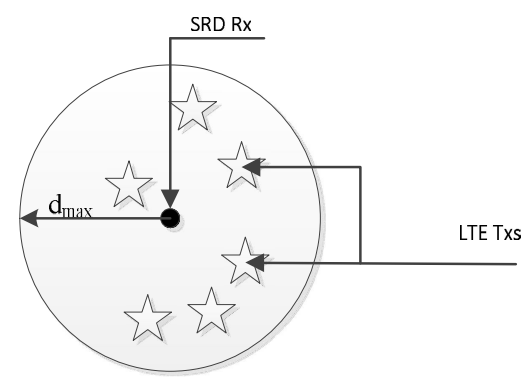

Fig. 1. SEAMCAT simulation general scenario.
LTE UE and SRD is in an open area up to $10 \mathrm{~m}$. The simulation radius was limited to $10 \mathrm{~m}$, in order to model the anticipated typical scenario of both LTE UE and SRD devices were placed in the same room. The Simulations distance between them varies stochastically up to $10 \mathrm{~m}$ radius. SRD $\mathrm{Rx} / \mathrm{Tx}$ simulation environment: propagation model - Extended Hata SRD, local environment - indoor. LTE UE Rx/Tx simulation environment: propagation model - Extended Hata, local environment - indoor. In the simulations were used 20000 calculations in each case. Distance between Interfering Link Transmitter (ILT) and Interfering Link Receiver (ILR) was calculated using real GSM network in Vilnius city. Average calculated coverage radius was $300 \mathrm{~m}$. SRDs operation radius was set to $40 \mathrm{~m}$.

\section{B. Results of Simulations}

Table III shows the results of simulations as separation distance is up to $10 \mathrm{~m}$.

TABLE III. INTERFERENCE PROBABILITY.

\begin{tabular}{|c|c|c|c|c|}
\hline & Annex 1 & Annex 7 & Annex 10 & Annex 13 \\
\hline $\begin{array}{l}\text { Interference } \\
\text { probability } \mathbf{1} \\
\text { dmax = 10 m }\end{array}$ & $23.56 \%$ & $15.89 \%$ & $37.91 \%$ & $21.52 \%$ \\
\hline
\end{tabular}

The obtained results show the noticeable level of probability of interference. The systems are electromagnetically compatible when the probability of interference is less than $5 \%$ [7]. Note that the interference criterion was used $\mathrm{C} /(\mathrm{I}+\mathrm{N})=8 \mathrm{~dB}$ or $17 \mathrm{~dB}$ for Annex 10 (as derived from the EN 300220 [11], EN 301357 [12] standards).

\section{PERformed MEASUREMENTS}

All measurements were conducted with certified equipment to replicate the interference scenarios simulated in theoretical analysis.

\section{A. Interference Scenario}

Semtech International AG SX1231 transceiver development kit was applied for the measurements to adopt real SRD. The main parameters of Semtech SX1231 device [13] are shown in Table IV.

TABLE IV. SEMTECH SX1231 TRANSCEIVER PARAMETERS.

\begin{tabular}{|c|c|}
\hline & Semtech SX1231 transceiver \\
\hline Frequency [MHz] & 868.1 \\
\hline Bandwidth [kHz] & 100 \\
\hline Throughput [kbit/s] & 57 \\
\hline Modulation & FSK \\
\hline EIRP [dBm] & -18 \\
\hline Antenna type & Omni \\
\hline Antenna gain [dBi ] & 0 \\
\hline
\end{tabular}

TABLE V. SRD SENSITIVITY LEVELS FROM DATASHEET.

\begin{tabular}{|c|c|c|}
\hline Bandwidth [kHz] & Bitrate [kbit/s] & Sensitivity [dBm] \\
\hline 5 & 1.2 & -118 \\
\hline 5 & 4.8 & -114 \\
\hline 40 & 38.4 & -105 \\
\hline
\end{tabular}

First of all the additional measurement was carried out in order to check whether the officially stated SRD sensitivity level corresponds to the actual running system parameters. The main information from datasheet is presented in 
Table V.

During the control measurement SRD Tx radiated power was set at $-18 \mathrm{dBm}$, bandwidth - $100 \mathrm{kHz}$, bitrate $57.5 \mathrm{kbit} / \mathrm{s}$. SRD Tx and Rx were then gradually removed from each other, monitoring incoming packages. During the experiment we observed that the connection was lost when the receive signal level dropped to an average of $-97 \mathrm{dBm}$.

Based on the established value of SRD sensitivity for given bandwidth, for the subsequent measurements of interference in the 2nd part of this study, the victim SRD receiver was set to operate at receive level $3 \mathrm{~dB}$ above the sensitivity level.

\section{B. LTE User Equipment Interferer}

Generation of LTE UE signal for this study was accomplished with the multi-purpose SDR development platform Ettus Research USRP2 device with WBX $50 \mathrm{MHz}-$ $2200 \mathrm{MHz} \mathrm{Rx} / \mathrm{Tx}$ daughterboard. This device is connected to the PC by Ethernet cable, so that the parameters of the generated signal can be adjusted on the computer. Main RF parameters of Ettus WBX $50 \mathrm{MHz}-2200 \mathrm{MHz} \mathrm{Rx} / \mathrm{Tx}$ daughterboard.

TABLE VI. MAIN LTE SIGNAL GENERATOR PARAMETERS

\begin{tabular}{|c|c|}
\hline & WBX 50-2200 MHz Rx/Tx \\
\hline Max output power [dBm] & 20 \\
\hline Frequency [MHz] & $50-2200$ \\
\hline Max bandwidth [MHz] & 40 \\
\hline $\begin{array}{c}\text { Connected antenna frequency } \\
\text { range [MHz] }\end{array}$ & $824-960$ \\
\hline Connected antenna gain [dBi] & 3 \\
\hline
\end{tabular}

With this device we simulated LTE UE operation, by setting the respective power level of interfering signal falling within the victim SRD channel to correspond to the LTE UE OOB emissions mask.

\section{INTERFERENCE SCENARIO II}

The measurement set up used two SRD devices (see Fig. 2): transmitter and receiver. The SRD equipment was placed and configured so that victim receiver operated with useful received signal level of $-94 \mathrm{dBm}$, corresponding to $3 \mathrm{~dB}$ margin over sensitivity level. Then the LTE UE interferer was switched on and brought gradually closer to victim SRD Rx, while constantly monitoring transmission of packets on victim SRD link.

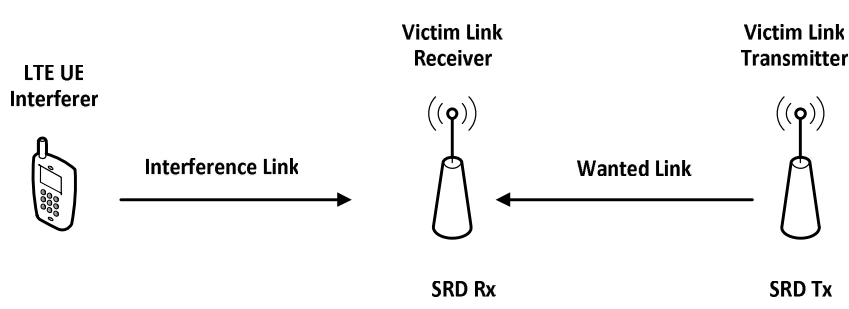

Fig. 2. Interference scenario II.

The stability of SRD link was monitored by performing cyclical count of proportion of packets received and decoded at the SRD Rx.

During the measurement, LTE UE interfering power did not exceed the OOB limits set in 3GPP TS 136101 . For this, the proxy LTU UE interferer was configured to radiate the equivalent $1 \mathrm{MHz}$ channel that spans the SRD Rx channel and is of power level directly corresponding to the 3GPP TS 136101 LTE UE OOB mask limit for given frequency separation between the interferer and victim. The following Fig. 3 shows the LTE UE spectrum emission mask overlaid on the SRD device channel.

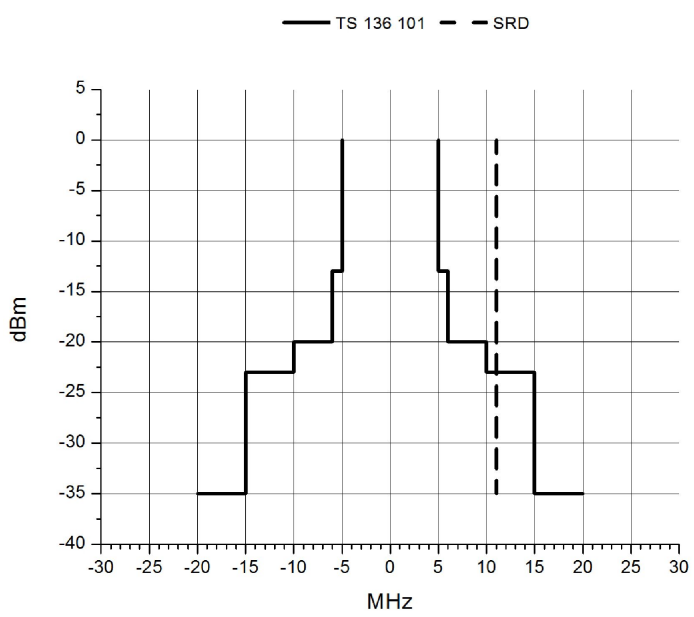

Fig. 3. LTE emission mask based on TS 136101 (RBW 100 KHz).

Figure 3 shows the LTE emission mask based on TS 136 $101(100 \mathrm{kHz}$ RBW) with SRD frequency $868.1 \mathrm{MHz}$. It demonstrates that LTE UE power shall not exceed -23 $\mathrm{dBm} / 100 \mathrm{kHz}$. The signal was developed to simulate specifically this part of LTE UE out of band emission.

\section{INTERFERENCE SCENARIO II RESULTS}

During the first measurement the proxy LTE UE interferer was brought gradually toward the SRD Rx, while monitoring the packet flow on victim link and trying to establish possible interruption. The following Fig. 4 shows the results obtained.

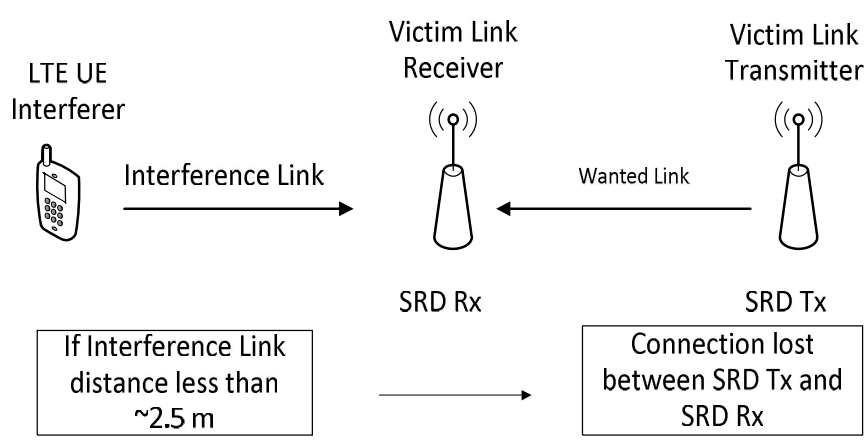

Fig. 4. Interference measurements.

The test revealed that when the separation distance between the LTE User Equipment as interferer and SRD Rx as victim is less than $\sim 2.5 \mathrm{~m}$, the interference severs the link between the SRD Tx and SRD Rx.

In the second measurement we calculated the percentage of packets being received at distances greater than $2.5 \mathrm{~m}$. During each measurement we sent a batch of 1000 packets and monitored how many of them were successfully received and decoded in SRD Rx. Semtech SX1231 transceiver may use two modes for coding data packages (FEC) Manchester and Whitening.

The analysis of SRD parameters indicates that usually 
they use Manchester coding method. It is similar to BiPhase, Manchester coding method affords a manner of adding the data rate clock information to the data packet on the end of receiving loop. Additionally Manchester benefits on the effortless an average DC level of $50 \%$ [14].

Whitening is so named because it introduces a pseudorandom element that makes the output appear more like white noise uniformly distributed. Whitening is typically implemented by using a maximal Linear-Feedback Shift Register (LFSR) to generate a repeating, pseudo-random pattern of bits that are XOR with the input data. Since XOR is reversible, the receiver can remove the noise from the data with its own LFSR that is synced to the transmitter [15].

Packages were sent with LTE UE interferer placed at respectively $2.7 \mathrm{~m}, 5 \mathrm{~m}$ and $7 \mathrm{~m}$ distances from victim SRD Rx. The Table VII shows the obtained results.

TABLE VII. RECEIVED PACKETS MEASUREMENTS

\begin{tabular}{|c|c|c|}
\hline \multirow{2}{*}{} & \multicolumn{2}{|c|}{ Received packets, \% } \\
\cline { 2 - 3 } & $\begin{array}{c}\text { Manchester } \\
\text { coding }\end{array}$ & $\begin{array}{c}\text { Whitening } \\
\text { coding }\end{array}$ \\
\hline $\mathbf{d m a x}=\mathbf{2 . 7} \mathbf{~}$ & 58 & 53 \\
\hline $\mathbf{d m a x}=\mathbf{5} \mathbf{~}$ & 96 & 74 \\
\hline $\operatorname{dmax}=\mathbf{7} \mathbf{m}$ & 97 & 96 \\
\hline
\end{tabular}

In this we can analyse the distribution of received packets, depending on the distance to the LTE UE interferer and coding algorithm. It appears that the Manchester algorithm is more resistant to interference. When the distance is greater than $5 \mathrm{~m}$, the interference effect nearly disappears.

\section{CONCLUSIONS}

This analysis examined the LTE UE $800 \mathrm{MHz}$ interference to SRD operating in the band of $863 \mathrm{MHz}-$ $870 \mathrm{MHz}$. The study was carried out in two methods: theoretical - simulations with SEAMCAT software and practical - measurements to verify results obtained in simulations.

The obtained results with SEAMCAT simulations show the noticeable level of probability of interference. Note that the interference criterion was used $\mathrm{C} /(\mathrm{I}+\mathrm{N})=8 \mathrm{~dB}$ or $17 \mathrm{~dB}$ for Annex 10 (as derived from the EN 300 220, EN 301357 , ECC Rep 037). Interference probability for nonspecific SRDs reach average $23.56 \%$, for alarms $-15.89 \%$, for radio microphones - $37.91 \%$, for wireless audio applications $-21.52 \%$.

The measurements revealed that the LTE UE out of band emission affects SRD devices. When the LTE UE interferer is placed less than $2.5 \mathrm{~m}$ from the victim SRD device (operating with $3 \mathrm{~dB}$ margin above sensitivity), the victim link is completely lost.

The LTE UE interference effect disappears at distances greater than average $5 \mathrm{~m}$ from victim receiver. Of the two FEC methods tested on victim link, it was observed that using Manchester coding algorithm can achieve greater resistance from interference than using Whitening coding algorithm. Note that all estimates reported here were obtained as mean averages of relevant samples of measurement results.

As a possible mitigation technique for interference avoidance could be not only spatial separation distance, but also upgraded duty cycle control in SRD systems, which could give an opportunity to avoid the redundant transmissions.

\section{REFERENCES}

[1] ECC Decision of 30 October 2009 on harmonised conditions for mobile/fixed communications networks (MFCN) operating in the band 790 - $862 \mathrm{MHz}, \mathrm{ECC} / \mathrm{DEC} /(09) 03,2009$.

[2] P. Chandhar, P. Ghosh, S. S. Das, "Performance analysis of cochannel deployment of femtocells with power control in 4G networks", Twentieth National Conf. Communications, 2014, pp. 16. [Online]. Available: http://dx.doi.org/10.1109/ncc.2014.6811377

[3] N. Himayat, et al., "Interference management for $4 \mathrm{G}$ cellular standards", IEEE Wireless Communications Magazine, vol. 48, no. 8 , pp. 86-92, 2010. [Online]. Available: http://dx.doi.org/10.1109/ MCOM.2010.5534591

[4] G. Boudreau, "Interference coordination and cancellation for $4 \mathrm{G}$ networks", IEEE Communications Magazine, vol. 47, no. 4, pp. 7481, 2009. [Online]. Available: http://dx.doi.org/10.1109/MCOM. 2009.4907410

[5] Relating to the Use of Short Range Devices (SRD), ERC Recommendation 70-03, 1997.

[6] European Commission Decision of 6 May 2010on harmonised technical conditions of use in the 790-862 MHz frequency band for terrestrial systems capable of providing electronic communications services in the European Union, Brussels, Belgium, 2010.

[7] SEAMCAT handbook, ECO, 2010.

[8] Frequency (channelling) arrangements for the 790-862 MHz band, CEPT Report 31, 2009.

[9] Evolved Universal Terrestrial Radio Access (E-UTRA). User Equipment (UE) radio transmission and reception, 3GPP recommendation TS 36.101 version 10.7.0 Release 10, 2012.

[10] Compatibility Of Planned Srd Applications With Currently Existing Radiocommunication Applications In The Frequency Band 863-870 $\mathrm{MHz}$, ECC Report 037, 2008.

[11] Electromagnetic compatibility and Radio spectrum Matters (ERM); Short Range Devices (SRD); Radio equipment to be used in the 25 $\mathrm{MHz}$ to $1000 \mathrm{MHz}$ frequency range with power levels ranging up to $500 \mathrm{~mW}$, ETSI EN 300220 standard, 2006.

[12] Electromagnetic compatibility and Radio spectrum Matters (ERM); Cordless audio devices in the range $25 \mathrm{MHz}$ to $2000 \mathrm{MHz}$, [4] ETSI EN 301357 standard, 2006.

[13] SX1231 Low Power Integrated UHF Transceiver datasheet SEMTECH, 2013

[14] Manchester coding basics, Atmel corporation, 2009.

[15] Measurements On The Performance Of Dvb-T Receivers In The Presence Of Interference From The Mobile Service (Especially From Lte), ECC Report 148, 2010. 